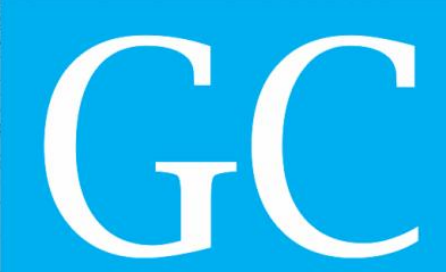

Revista Nacional de Gerenciamento de Cidades National Journal of Cities Management

\title{
REDES DE TRANSPORTES E CIDADES: UMA ABORDAGEM AO MOVIMENTO TDR
}

\author{
Fander de Oliveira Silva \\ Diego Armando Céspedes Àlvarez ${ }^{2}$
}

\begin{abstract}
RESUMO
Estar em rede torna-se uma obrigação e construir um arco de fixos e fluxos diz-se ocupar-se em um lugar no território. Dado os interesses e ações do Poder Público sob influências das grandes empresas, as redes vão (re)configurar as cidades, promover níveis de complexidade e eficácia territorial, podendo ser redes equilibradas como também redes desarmônicas. Neste sentido, a presente análise de situação é feita a partir de fundamentos teóricos e revisões bibliográficas. O texto apresenta a discussão dos conceitos territorialização-desterritorialização-reterritorialização de Raffestin (1984), possibilitando ao final uma reflexão da importância das redes de transportes no planejamento territorial das cidades, a qual Uberlândia se torna referência, e o futuro promissor das discussões que a envolve.
\end{abstract}

PALAVRAS-CHAVE: Redes de Transportes. Planejamento Urbano. TDR.

\section{TRANSPORT OF NETWORKS AND CITIES: AN APPROACH TO MOVE TDR}

\begin{abstract}
Be networking becomes a must and build an arc of fixed and streams is said to occupy a place in the territory. Given the interests and actions of the government under the influence of large companies, networks will (re) configure the cities, promoting levels of complexity and territorial effectiveness, and can be balanced networks as well as inharmonious networks. In this sense, this situation analysis is made from theoretical and literature reviews. The text presents a discussion of the concepts territorialdispossession, repossession of Raffestin (1984), enabling the end reflection of the importance of transport networks in the territorial planning of cities, which Uberlandia becomes reference, and the promising future of the discussions that it involves.
\end{abstract}

KEYWORDS: Transport Networks. Urban Planning. TDR.

\section{REDES DE TRANSPORTE Y CIUDADES: UNA APROXIMACIÓN AL MOVIMIENTO TDR}

\footnotetext{
${ }_{1}^{1}$ Geógrafo, Universidade Federal de Uberlândia. fanderoliveira@hotmail.com.

${ }^{2}$ Geógrafo, Universidade Nacional de Costa Rica. diegouna.geo@gmail.com.
} 

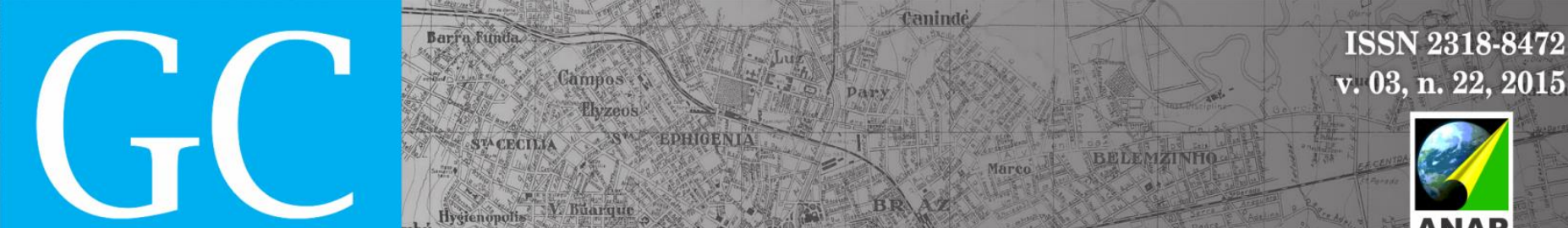

Revista Nacional de

\section{RESUMEN}

Sé de una red se convierte en una necesidad y construir un arco de fijo y arroyos se dice a ocupar un lugar en el territorio. Teniendo en cuenta los intereses y las acciones del gobierno bajo la influencia de las grandes empresas, las redes se (re) configurar las ciudades, la promoción de niveles de complejidad y eficacia territorial, y se puede equilibrar las redes, así como las redes inarmónicas. En este sentido, este análisis de la situación se hace a partir de comentarios teóricos y la literatura. El texto presenta una discusión de los conceptos territorial-despojo, la recuperación de Raffestin (1984), lo que permite el reflejo final de la importancia de las redes de transporte en la planificación territorial de las ciudades, lo que se convierte en Uberlandia de referencia, y el futuro prometedor de las discusiones que involucra.

PALABRAS CLAVE: Redes de Transporte. La planificación urbana. TDR.

\section{INTRODUÇÃO}

Até a Primeira Revolução Industrial o mundo era exprimido em um conjunto de realidades espaciais onde a sociedade se organizava na infinita diversidade cultural, política e econômica, em um espaço interminável de gêneros de vida. Desde este marco no século XVIII, a tecnologia e a informação passaram a ter o papel importante de intervenção no ordenamento territorial e no remodelamento dos costumes das civilizações, na unificação de espaços e na uniformização das relações sócio-comerciais.

Partindo a segunda Revolução Industrial, marco do século $X X$, tal intervenção é intensificada e passa agir em escala mundial, compactando modos de vida e induzindo cada vez mais o processo contínuo de produção. O tema "globalização" passa a ser pauta das discussões mundiais e o discurso de um processo que domina de maneira incontrolável e irreversível a economia mundial faz com que as fronteiras nacionais comecem a ser estremecidas e dilaceradas.

Evidentemente, colocada entre aspas a "globalização" como ideologia de progresso tem seu fundamento de realidade pela qual a velocidade do progresso técnico científico nas áreas de informática, telecomunicações e finanças associadas às inovações tecnológicas, a diminuição dos custos de transporte e por conseqüência de mercadorias e liberalismo comercial tem garantido a crescente 
integração comercial e financeira mundial, internacionalizando as relações sócioespaciais.

Nos últimos anos marcados por encontros e desencontros conceituaisempíricos, ela tem ganhado importância estratégica no planejamento das cidades. Todos os processos de integração produtiva, integração de mercado, integração de pessoas, integração econômica, integração de informação implicaram principalmente em estratégias de circulação e comunicação, perfazendo o que chamamos de redes.

Pensando a rede não apenas enquanto mais uma forma (abstrata) de composição do espaço, no sentido de um 'conjunto de pontos e linhas', numa perspectiva euclidiana, mas como 0 componente territorial indispensável que enfatiza a dimensão temporal-móvel do território e que, conjugada com a 'superfície' territorial, ressalta seu dinamismo, seu movimento, suas perspectivas de conexão ('ação distância', como destaca Machado, 1998) e 'profundidade' relativizando a condição estática e dicotômica (em relação ao tempo que muitos concedem ao território enquanto território-zona num sentido mais tradicional. (HAESBAERT, 2004, p. 286-87).

Apesar de nunca se ter existido uma sociedade sem redes (no sentido técnico ou mesmo social) é sob a "globalização" que elas vão dominar estrategicamente com diferentes intensidades e ritmos os fluxos, introduzindo novos aspectos geopolíticos de acordo com os interesses de quem a comanda. Mudam se assim a natureza e o modo de fazer geopolítica

A densificação destas redes, segundo Dias (2001), internamente organizadas e compartilhadas entre diferentes agentes regionais, nacionais ou internacionais, tem surgido como condição que se impõe a sobrevivência da sociedade contemporânea. Os fluxos de pessoas até ao de informações pressupõe a existência das redes, que surge como instrumento que vai viabilizar exatamente as duas estratégias: circular e comunicar pessoas, bens, mercadorias, serviços e informações. Estar em rede torna-se uma obrigação e construir um arco de fixos e fluxos diz-se ocupar-se em um lugar no território. 


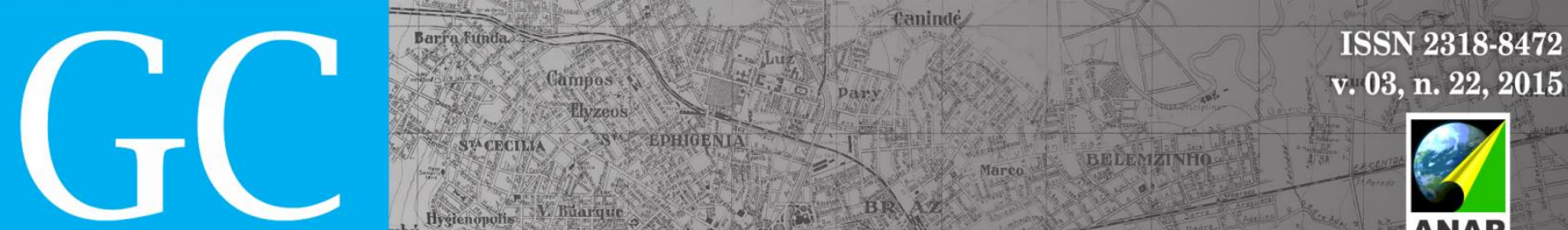

Revista Nacional de

diária de circulação, faltas de área de carga e descarga e estacionamentos, infraestrutura precária, falha de comunicação, entre outros são os problemas mais comuns encontrados.

\section{OBJETIVOS}

O estado de prostração técnica e intelectual do Poder Público no que se refere às redes de transportes desconexos a um planejamento integrado urbano tem corroborado para que a leitura entre território e redes fosse compreendida como duas unidades distintas e fragmentadas, não se percebendo que a rede é um elemento constituinte do território e vice-versa. Assim para superar esta dicotomia começaremos por avaliar conceitualmente e o papel das redes de transportes de Uberlândia sobre o território e os rumos que sugestivamente podem ser tomados.

\section{MÉTODO DE ANÁLISE}

O estudo foi desenvolvido com base no método dedutivo e na investigação científica sobre a realidade social, a partir dos fundamentos teóricos e revisões bibliográficas aplicadas a situações e problemas concretos no contexto da realidade das cidades brasileiras, em específico Uberlândia.

\section{FEIÇÕES TERRITORIAIS}

A noção de Território aqui será entendida em um sentido amplo em que Guattari e Rolnik (1986) ultrapassam o uso que fazem dele. O território é relativo tanto a um espaço vivido, quanto a um sistema em que o sujeito se sente em "seu lugar", é sinônimo de apropriação e subjetividades pelas quais vão favorecer uma série de comportamentos, investimentos, tempos e escalas, intensidades e direções sejam elas sociais, políticas, econômicas, ambientais e culturais. 

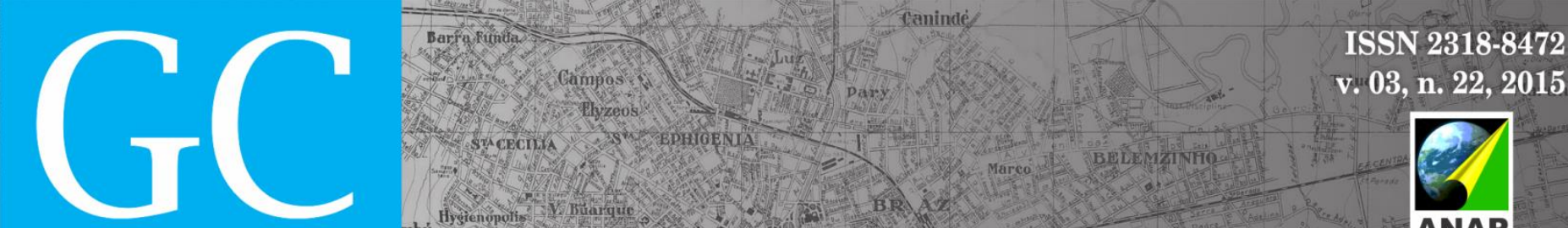

Revista Nacional de

Neste sentido, podemos enfatizar que sempre houve territórios descontínuos, desde o período Colonial em que os comerciantes tinham suas bancas comerciais nas feiras livres de Caruaru, Feira de Santana, Campo Grande, São Paulo, e outras cidades onde se propagava marchas para desbravar o Oeste e se realizavam peregrinações de devoção religiosa.

O território é o chão e mais a população, isto é uma identidade, o fato e o sentimento de pertencer àquilo que nos pertençe. O território é a base do trabalho, da residência, das trocas materiais e espirituais e da vida, sobre as quais ele influí. Quando se fala em território deve-se, pois, de logo, entender que está falando em território usado, utilizado por uma população. (SANTOS, 2000, p.96, grifo nosso).

O novo e diferente agora é a intensidade e qualidade com que estes territórios se organizam em rede. Conforme afirma o autor, o território é também trocas materiais e espirituais (movimento, ritmo, fluxo, rede) e não se trata de movimentos meramente funcionais, mas também de significados e expressividade para o quem constrói e usufrui, são dotados de nós e arcos, fixos e fluxos. Nesta perspectiva o território não é uma categoria de forma abstrata no espaço, mas sim um componente espacial que proporciona vida e dimensão espaço-temporal e mobilidade a superfície, constituindo-se a rede como modo de estruturação superficial das interações espaciais. A sociedade pode perfeitamente se definir como uma rede de redes sociais não exclusivas que se desdobram num mundo material, sempre mais ou menos territorializadas.

[...] a rede aparece [...] como fios seguros de uma rede flexível que pode se moldar conforme as situações concretas e, por isso mesmo, se deformar para melhor reter. A rede é proteiforme, móvel e inacabada, e é desta falta de acabamento que ela tira sua força no espaço e no tempo: se adapta as variações no espaço e as mudanças que advém do tempo. A rede faz e desfaz as prisões do espaço, tornando território: tanto libera como aprisiona. (RAFFESTIN, 1993, p.86).

A rede torna-se um instrumento de ação dos atores hegemônicos no território. No dizer de Santos (1999), o território torna-se suporte das redes, como 


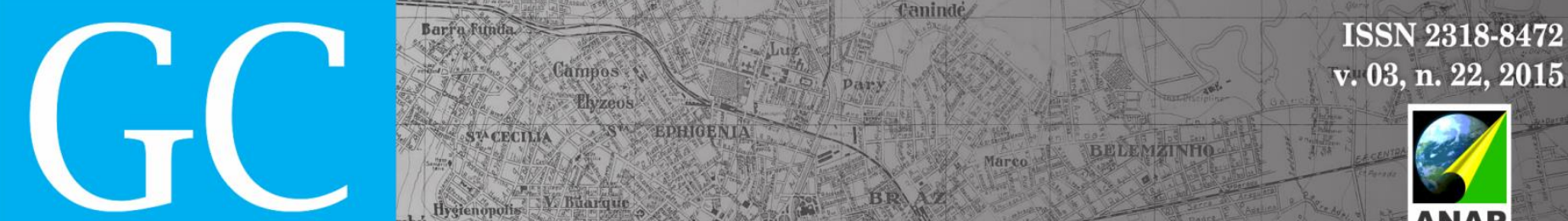

Revista Nacional de

focos de geração e atração de fluxos que subalternados tem seu papel desenvolvimentista no que concerne a mobilidade sustentável e a reprodução do capital, como também de indução a segregação espacial, a "aglomerados de exclusão" na ressalva de Haesbaert (2007).

Como vimos a desterritorialização também está ligada a uma noção de território (funcional e cultural), daí podemos reconhecer que o processo de desterritorialização está intimamente imbricado no processo de uma reterritorialização. Podemos estar territorializados no sentido concreto funcional, mas também reterritorializados no sentido simbólico e cultural. Isto é, produtos sócioespaciais dos movimentos e interações espaciais regidos sob as forças econômicas, políticas e culturais que utilizam das suas estratégias para determinar onde, quando e em que tempo se dará os processos se contextualizará os processos territorialização-desterritorialização-reterritorialização (TDR) como apontara Raffestin (1984).

As restrições impostas à rede, seja pelas condições físicas, funcionais e/ou econômicas do território esclarecem a sua larga permanência no tempo, no ordenamento do território e nos seus vários efeitos. Restrições que podem ser superadas pela evolução econômica e tecnológica, embora esta tenha contribuído pelo menos no Brasil para reforçar modelos históricos de transportes, no caso rodoviário.

As redes de transportes podem então ser enxergadas como componentes territoriais e prestarem serviços tanto estruturadores como desestruturadores. Esta dinâmica se tornou tão importante na modernidade que alguns autores já se remetem ao termo "rede-território".

\section{UMA APLICAÇÃO À UBERLÂNDIA}



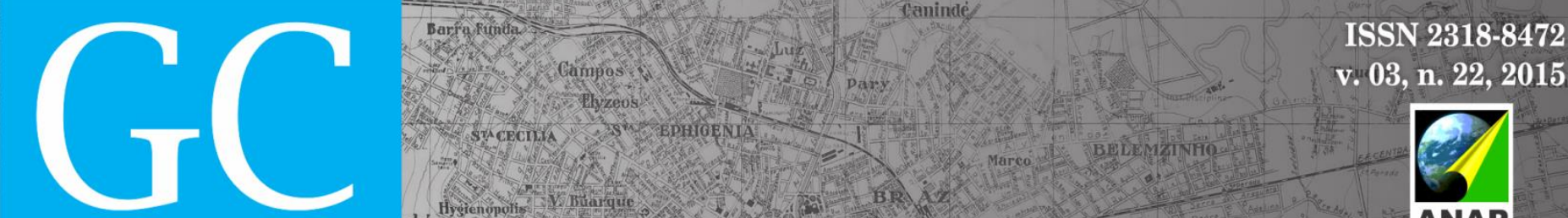

Revista Nacional de

A constituição da rede de transportes no Brasil como um dos principais componentes na gestão e ordenamento do território é recente e marcada pela associação de modernização e integração sócio-econômica. Com a extinção de barreiras comerciais, instalações e adequações de infra-estruturas territoriais, avanços tecnológico-informacionais e políticas de mobilidade a integração intra e interurbana das cidades brasileiras, como é o caso de Uberlândia, pressupôs a promoção complementar da economia nacional, se tornando condição aos movimentos entre as cidades glocalizadas.

As estratégias de flexibilidade e rapidez das redes de transportes deram livres acessos a um jogo de disputas de interesses em função de interesses na maioria das vezes corporativos.

Como a lógica de instalação ou adequação das infra-estruturas territoriais de transporte é muito dependente das demandas na maioria das vezes ligadas ao trabalho da produção hegemônica, a integração territorial ocorre, principalmente nos países pobres, em função de interesses corporativos (CASTILLO, 2005, 2006 apud PEREIRA, 2009, p. 124).

Uberlândia, considerada uma das principais cidades médias brasileiras com estimativa populacional para 2015 de 654.681 mil habitantes e com índice de 1 veículo para 1,69 morador (IBGE, 2010) tem seu processo histórico e de formação um ligeiro crescimento populacional e adensamento urbano, pelo qual não foi acompanhado pela melhoria e qualidade de vida. A localização privilegiada, no centro de uma malha viária que liga os quatro pontos cardeais do País, foi decisiva para que Uberlândia (MG) virasse um importante centro de distribuição de mercadorias.

Segundo Rocha (2008) a cidade é dotadas das cinco maiores empresas atacadistas do Brasil (Martins, Arcom, Peixoto, Aliança e União) e mantêm uma frota de caminhões e carretas de três mil equipamentos, gerando mais de nove mil empregos diretos e indiretos, sendo mais de 700 mil clientes espalhados pelo Brasil, 


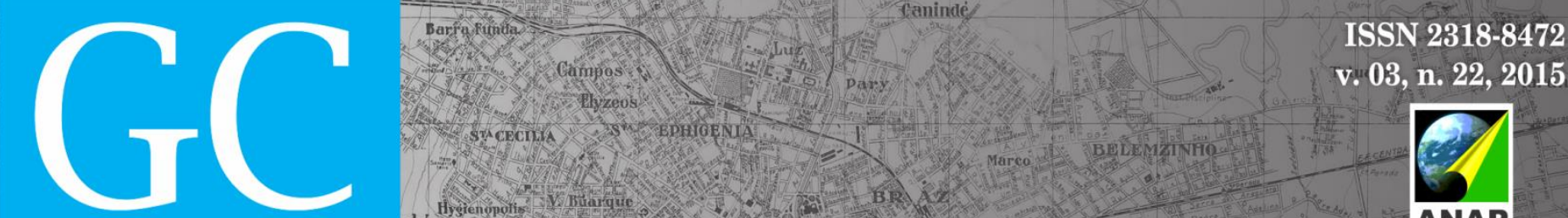

Revista Nacional de

outras tem compreendido as redes de transportes como "transporte de pessoas", priorizando o transporte público e não enfrentam o transporte de cargas e informações como uma prerrogativa no planejamento e isso acaba se reproduzindo nas políticas municipais. No entanto, temos cidades como São Paulo, Porto Alegre, Curitiba, Cascavel que asseguram em seus planos a mobilidade de cargas e apontam à um planejamento que minimiza os custos de tempo e espaço, usa recursos renováveis, racionalização e promovem eficácia nos fluxos e caminham na garantida da igualdade de acesso e recursos, na proteção e saúde ambiental e no desenvolvimento econômico.

Sobre as funções dos centros urbanos brasileiros, as distâncias entre casa e trabalho, entre fornecedor-cliente, origem-destino, geram fluxos de pessoas, bens e serviços, trazendo inúmeros problemas já comentados. Tal situação, bem como o papel do Poder Público e do Setor Privado (no que se refere às redes de transportes) precisa ser colocado em pauta nas políticas tanto federais quanto municipais e na prática, no lócus urbano, objetivando-se o bem estar comum que garanta o direito igual do acesso à cidade.

O estudo das redes de transportes tem grande importância como instrumento para o planejamento territorial, seja na escola primária, na Universidade ou nas associações de bairros. É importante que esta análise não ocorra unicamente nas cadeiras eleitas.

\section{REFERÊNCIAS BIBLIOGRÁFICAS}

DIAS, L. C. Redes: emergência e organização. In: CASTRO, Iná Elias; GOMES, Paulo César da Costa; CORRÊA, Roberto Lobato (Org.) Geografia: Conceitos e temas. 3 ed. Rio de Janeiro: Bertrand Brasil, 2001. p. 141-162.

GUATTARI, F.; ROLNIK, S. Micropolítica: cartografias do desejo. 2.ed. Petrópolis: Vozes, 1986.

HAESBAERT, Rogério. Identidades territoriais: entre a multiterritorialidade e a reclusão territorial (ou: do hibridismo cultural à essencialização das identidades). In: ARAÚJO, Frederico Guilherme Bandeira de; HAESBERT, Rogério (Org.). Identidades e territórios: questões e olhares contemporâneos. Rio de Janeiro: Access, 2007. Cap. 02, p. 33 a 56. 


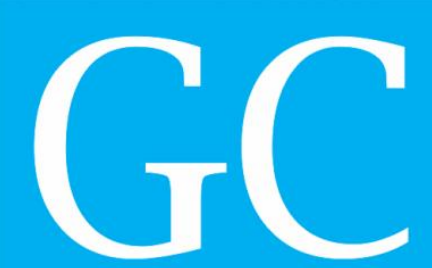

Revista Nacional de

Gerenciamento de Cidades

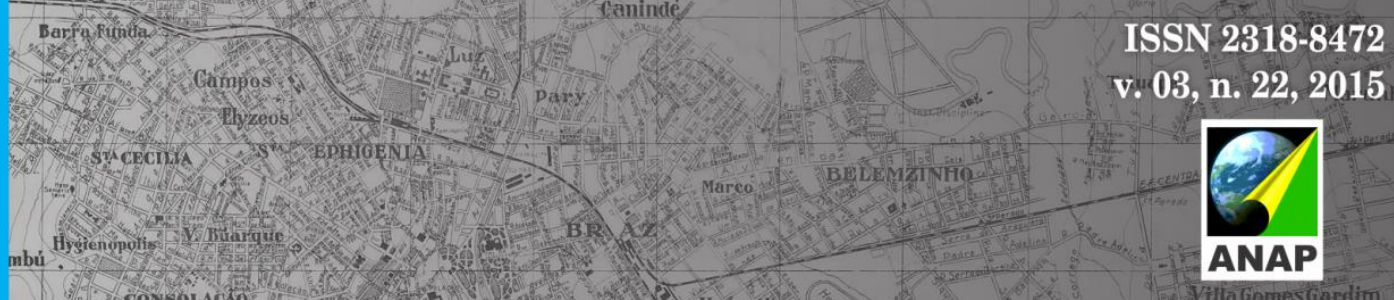

DOI: $10.17271 / 2318847232220151158$

HAESBAERT, Rogério. O mito da desterritorialização: do "fim dos territórios" à multi territorialidade. Rio de Janeiro: Bertrand Brasil, 2004.

INSTITUTO BRASILEIRO DE GEOGRAFIA E ESTATÍSTICA (IBGE). Censo Demográfico de 2010. Rio de Janeiro: IBGE, 2011. Disponível em: http://censo2010.ibge.gov.br/. Acesso em: 18 de setembro de 2014.

PEREIRA, M. F. V. . Redes, sistemas de transporte e as novas dinâmicas do território no período atual: notas sobre o caso brasileiro. Sociedade \& Natureza (UFU. Impresso), v. 21, p. 121-129, 2009.

PONS, J. M.S.; REYNÉS, M. R.M. Geografía de los Transportes. Palma (Illes Balears): Universitat de les Illes Balears: Gráficas Planisi, S.A. 2004. p. 444.

RAFFESTIN C., Territorializzazione, deterritorializzazione, riterritorializzazione e informazione, In: Turco A., Regione e regionalizzazione, Milano, Franco Angeli, 1984, p.69-82.

RAFFESTIN, C. Por uma geografia do poder. São Paulo: Ática, 1993.

ROCHA, Guto. Uberlândia quer ser a capital da logística. Revista Carga Pesada. Edição 153. Disponível em <http://www.cargapesada.com.br/edicoesanteriores/edicao153/edicao153.php?id=214>. Acesso em 22 de maio de 2015.

SANTOS, Milton. A natureza do espaço: técnica e tempo, razão e emoção. $3^{a}$ Ed. São Paulo: Hucitec, 1999.

SANTOS, Milton. Por uma outra globalização - do pensamento único à consciência universal. Rio de Janeiro: Record, 2000.

VASCONCELLOS, E. A. de. Políticas de Transporte no Brasil: a construção da mobilidade excludente. Barueri, SP: Manole Ltda. $1^{\circ}$ ed. 2014. 